\title{
Research summary of cable channel fire extinguishing technology
}

\author{
LIU Sanwei ${ }^{1, *}$, HUANG Fuyong ${ }^{1}$, GONG Liang ${ }^{2}$, DUAN Xiaoli ${ }^{1}$, CHAO Yafeng ${ }^{1}$, DUAN Jianjia ${ }^{1}$, YUE Yishi ${ }^{1}$ \\ ${ }^{1}$ State grid Hunan electric power co, LTD. Electric power research institute, 41000, Changsha China \\ 2State grid Hunan electric power co, LTD. Changde Power supply company, 41500, Changde China
}

\begin{abstract}
Cable channel fire is an important factor affecting the safe operation and maintenance of power cables. This paper summarizes the current research situation of fire-extinguishing technology, analyzes the fire-extinguishing technology suitable for cable channel, and proposes to use S-type aerosol fireextinguishing technology to extinguish the fire of cable channel..
\end{abstract}

\section{INTRODUCTION}

Since 1960, 62 major fire accidents have occurred in power plants, substations and power supply tunnels in China due to the spread of cable fire, which has destroyed $32 \mathrm{~km}$ of cable and many electrical installations, resulting in a direct loss of tens of millions of yuan[1]. More than 10 billion $\mathrm{kw} \cdot \mathrm{H}$ of power generation will be missed, and the loss of electricity sold will be more than 700 million yuan. In the above 62 cable fire accidents, there were 15 fire delays due to cable fault, accounting for $24.2 \%$ of the total number of times, among which 7 were caused by declining insulation and aging. In addition, there were cable head explosion, overload short circuit and so on. The external ignition and ignition of the cable were 47 times, accounting for $75.8 \%$ of the total[2]. The causes of the fire include oil leakage at the flange of the oil pipe, excessive accumulation of coal powder, failure of oilcontaining electrical equipment, explosion, oil injection, accidental ignition of combustible materials left by construction, etc[3-4].

Cable fire accident has the following characteristics: All kinds of cables, including oil-paper insulated cable, high voltage oil-filled cable, rubber insulated cable, plastic insulated cable (including cross-linked polyethylene insulated cable and PVC insulated cable), have occurred over fire, burning; In the open space layout of less than 3 layers of cable, even if the oil-paper insulated cable[5], it often can also extinguish in the fire. Many fire accidents so cause many units or even the whole factory (station) sex stop production, because of the important loop cable fire, lost the backup power supply or important public power supply. So that the fire pump, accident lighting power off, can not early extinguish the fire, exacerbating the fire loss. After the cable caught fire in the tunnel[6], because of the precipitation of smoke choking, fire extinguishing difficult to carry out. In particular, PVC cable fire after the precipitation of hydrogen chloride gas, the need to wear a gas mask firefighters to enter, often delayed the timely fire.(5) Lay out cable sites in multiple layers such as the main building and tunnel of the power generation factory. After the cable catches fire, it will spread to adjacent cables, which will increase the burning intensity and speed up the burning along the cable line.

\section{CABLE FIRE ACCIDENT CAUSE}

According to the classification and statistics of cable fire accident causes, we know that the external causes account for a large proportion, among which the fire caused by the burning of combustible materials and buildings around the cable is more common[7-8], as Table. 1 shows.

Fire caused by a fire in the cable itself, as Fig.1 shows:

a) By the ground wire and short circuit when the overcurrent caused by heat fire

b) Local heating and fire due to improper connection of the conductor;

c) Fire caused by insulation damage caused by aging of the insulator.

Fire caused by an external fire,as Fig. 1 shows::

a) Fire caused by welding sparks during construction;

b) Fire caused by overheating of the cable-connected machine;

c) Fire caused by burning oil and other combustibles and buildings.

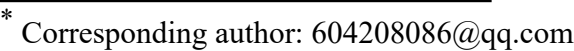




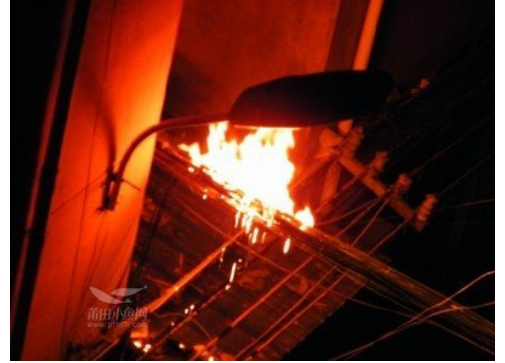

Fig. 1. Fire caused by a fire in the cable itself.

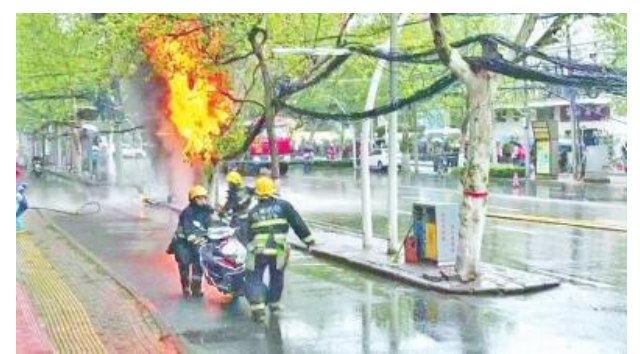

Fig. 2. Fire caused by an external fire.

Table 1. Cable fire accident cause

\begin{tabular}{|c|c|}
\hline \multirow{3}{*}{$\begin{array}{l}\text { Fire caused by a fire } \\
\text { in the cable itself }\end{array}$} & $\begin{array}{c}\text { Cable material impure or } \\
\text { unqualified }\end{array}$ \\
\hline & $\begin{array}{c}\text { Cable production process } \\
\text { poor technology, product } \\
\text { quality defects }\end{array}$ \\
\hline & $\begin{array}{l}\text { Damaged cables due to } \\
\text { improper transport storage }\end{array}$ \\
\hline \multirow{7}{*}{$\begin{array}{l}\text { Fire caused by an } \\
\text { external factor }\end{array}$} & $\begin{array}{l}\text { Cable laying and installation } \\
\text { do not meet the requirements }\end{array}$ \\
\hline & $\begin{array}{l}\text { The fire protection of the } \\
\text { cable line is not up to } \\
\text { standard }\end{array}$ \\
\hline & Mechanical damage \\
\hline & Overvoltage \\
\hline & $\begin{array}{c}\text { Influence of neutral } \\
\text { grounding mode on } \\
\text { distribution cable }\end{array}$ \\
\hline & $\begin{array}{l}\text { Improper use and } \\
\text { maintenance }\end{array}$ \\
\hline & Poor operating conditions \\
\hline
\end{tabular}

\section{Cable channel fire extinguishing technology}

\subsection{Gas extinguishing technique}

Mainly for carbon dioxide fire extinguishing technology, using carbon dioxide density is higher than the characteristics of air, in the fire area spray a large amount of carbon dioxide, carbon dioxide covered in the fire area, isolated the air, so as to achieve the effect of fire extinguishing[9]. Gas fire-extinguishing technology is a traditional fire-extinguishing technology. Since carbon dioxide covering in the air indicates slow speed and low fire-extinguishing efficiency, it has been gradually replaced by other fire-extinguishing technologies in recent years

\subsection{Water mist fire extinguishing technology}

The application of fine water mist in fire fighting began in the 1940s, when it was mainly used in special places, such as means of transport.

Water Mist is the opposite of water spray, which is tiny particles of water produced by using a special nozzle and spraying water at high pressure. In NFPA 750, fine water mist is defined as a water particle with a diameter of Dv0.99 of the coarsest part of the mist not greater than 1000 , measured on a plane $1 \mathrm{~m}$ from the nozzle, at a minimum design working pressure.

Due to the small diameter of water mist droplets, compared with the same volume of water, its surface area increases dramatically, thus enhancing the efficiency of heat exchange and playing a very good cooling effect. After absorbing heat, the fine water mist is quickly vaporized, making the volume expand rapidly, usually reaching more than 1700 times, thus reducing the oxygen concentration in the air, inhibiting the speed of oxidation reaction in combustion, and playing a role of suffocation. It can be seen that the fire extinguishing mechanism of fine water mist: first, the cooling efficiency, heat absorption; Second, asphyxiation, blocking oxidation reaction. In addition, fine water mist has a very superior efficiency of blocking heat radiation transfer, and can effectively block the intense heat radiation.

\subsection{Superfine dry powder extinguishing technology}

Ultrafine dry powder fire extinguishing agent is mainly composed of active fire-extinguishing components, hydrophobic components and inert fillers. The hydrophobic components are mainly silicon oil and hydrophobic silica, and there are various inert fillers, which mainly play the roles of anti-vibration and agglomerating, improving the movement performance of dry powder, catalyzing the polymerization of dry powder silicone oil and improving the co-capacity with foam fire extinguishing agent. This kind of common dry powder extinguishing agent has been widely used at home and abroad[10].

The fire-extinguishing components are the core of dry powder fire-extinguishing agents. The fireextinguishing substances that can play a fireextinguishing role mainly include: $\mathrm{K}_{2} \mathrm{CO}_{3}, \mathrm{KHCO}_{3}$, $\mathrm{NaCl}, \mathrm{KCl},\left(\mathrm{NH}_{4}\right)_{2} \mathrm{SO}_{4}, \mathrm{NH}_{4} \mathrm{HSO}_{4}, \mathrm{NaHCO}_{3}, \mathrm{~K} 4 \mathrm{Fe}(\mathrm{CN})_{6}$ - $3 \mathrm{H}_{2} \mathrm{O}, \mathrm{Na}_{2} \mathrm{CO}_{3}$, etc. Domestic products have been produced: ammonium phosphate, sodium bicarbonate, sodium chloride, potassium chloride dry powder fireextinguishing agent. Each fire particles have a cap on the critical particle size, less than the critical size of particles all fire extinguishing effect, extinguishing efficiency is greater than the critical size of particles sharply reduced, but the momentum is big, aerodynamic force on the 
small particles through air, forcing small particles, followed by pouncing on the flame center, rather than before the flame was blown away, a stream of lower extinguishing efficiency. The particle size of common dry powder extinguishing agent is between $10 \sim 75 \mathrm{~m}$, which has poor dispersion and relatively small specific surface area[11].

Therefore, the total specific surface area of quantitative dry powder is small, the mass of a single particle is large, the sedimentation rate is fast, and the decomposition rate is slow when heated, resulting in its ability to capture free radicals is small, so its extinguishing ability is limited, which limits the scope of dry powder extinguishing agent to some extent. The particle size of dry powder extinguishing agent is directly related to its extinguishing efficiency. The larger the critical particle size of extinguishing component is, the better the extinguishing effect is. Therefore, it is a very effective means to improve the extinguishing efficiency of dry powder by preparing ultra-fine powder which can be uniformly dispersed and suspended in the ignition space, ensuring the activity of extinguishing component particles and reducing the amount of extinguishing agent per unit space.

\subsection{Aerosol fire extinguishing technology}

Aerosol fire-fighting technology is a new fire-fighting technology developed on the basis of military firework technology. The first generation of aerosol fire-fighting technology, also known as smoke fire-fighting technology, was born in China in the early 1960s. It was completed by researchers from tianjin Fire Research Institute of public Security. They independently developed the automatic smoke extinguishing system, which is mainly used to extinguish fires in class A, B and $\mathrm{C}$ liquid storage tanks. Aerosol fire-fighting technology is a new fire-fighting technology developed on the basis of military firework technology. In the 1960s, the tank smoke extinguishing technology studied by tianjin Fire Research Institute of the Ministry of Public Security was the earliest aerosol extinguishing technology. At that time, this new extinguishing technology did not arouse wide attention[12].

Aerosol fire-fighting technology is a new firefighting technology developed on the basis of military firework technology. Aerosol is generally a fine solid or liquid particles dispersed in the gas formed by the stable state system, professional refers to the gas (usually air) as a dispersion medium, to the solid or liquid particles as a dispersion of colloidal system. $\mathrm{K}$ type aerosol fire extinguishing technology is also called potash class fire extinguishing technology, is the second phase of the aerosol fire extinguishing technology development, this kind of aerosols in agent mainly USES the potassium nitrate as the main antioxidant, the discharge material fire extinguishing efficiency is high, but because it contains a lot of potassium, easy to moisture absorption, form a kind of yellow sticky strongly basic conductive liquid film, this kind of material for electronic equipment has a great deal of damage, so the $\mathrm{K}$ type automatic aerosol fire extinguishing device cannot be used in electronic equipment, precision instruments, and cultural relic archives.

The third-generation aerosol (S-type) is mainly composed of strontium salt as the main oxidant, and the second-generation potassium salt (K-type) aerosol is different. Strontium ion does not absorb moisture, does not form conductive solution, and does not cause damage to electrical equipment. The s-type aerosol automatic fire suppression product was first independently developed by (Shaanxi Ken-Rui) in the early 21 st century.

The fire-extinguishing mechanism of S-type aerosol is as follows:

Endothermic cooling extinguishing mechanism

Metal salt particles absorb a large amount of heat at high temperature, which leads to physical endothermic processes such as thermal melting and gasification, and the flame temperature is reduced, and then the heat radiated to the burning surface of combustible materials for gasification of combustible molecules and decomposition of the vaporized combustible molecules into free radicals will be reduced, and the combustion reaction rate will be restrained to a certain extent.

Fire extinguishing mechanism.

a) Gas phase chemical inhibition: under the action of heat, the decomposed vaporized metal ions or the cation losing electrons in the fire-extinguishing aerosol can have an affinity reaction with the active groups in combustion, repeatedly consuming a large number of active groups and reducing the combustion free radicals.

b) Solid phase chemical inhibition: the particle size in the fire-extinguishing aerosol is very small $\left(10^{-9} \sim 10^{-}\right.$ $\left.{ }^{6} \mathrm{~m}\right)$, with a large surface area and surface energy, which can absorb the active groups in combustion, and produce chemical action to consume a large number of active groups and reduce the combustion free radicals.

c) Reducing oxygen concentration: $\mathrm{N}_{2}$ and $\mathrm{CO}_{2}$ in fire-extinguishing aerosol can reduce oxygen concentration in combustion, but the rate is slow, and the fire-extinguishing effect is far less than heat absorption cooling and chemical inhibition.

\section{Conclusion}

Although aerosol technology in China has the earliest history of development and has reached the world's leading level, as a new type of fire extinguishing product, the relevant national specifications are in the stage of continuous improvement.

China's "Fire Law" clearly stipulates: "The state encourages and supports scientific research and technological innovation in fire control, and promotes the use of advanced fire control and emergency rescue technology and equipment."[13] To sum up, s-type aerosol fire extinguishing technology is especially suitable for cable channel fire extinguishing due to its characteristics of university and cleaning. 


\section{References}

1. GRAYSON $\mathrm{S}$ J,HEES $\mathrm{P}$ V,GREEN $\mathrm{A}$ M,et al.Assessing the fire performance of electric

2. BERTRAND R, CHAUSSARD M, GONZALEZ R, et al.Behavior of electrical cables under fire conditions[J].Kerntechnik, 2002,67(2/3):116-120.

3. BERG H P, PILJUGIN E, HERB J, et al. Comprehensive cable failures analysis forprobabilistic fire safety assessments[J]. Reliability:Theory and Applications, 2012 , 1(1):3649.

4. HOSTIKKA $\mathrm{S}, \quad$ KESKI-RAHKONEN O.Probabilistic simulation of fire scenarios[J]. Nuclear Engineering and Design,2003,224:301-311.

5. LEE Y H,KIM J H,YANG J E.Application of the CFAST zone model to the fire PSA[J]. Nuclear Engineering and Design,2010,240:3571-3576.

6. EE M H,MOOM C K,KIM H T.Performance-based fire fighting strategies for confined fire zones in nuclear power plants[J].Progress in Nuclear Energy,2013,62:16-25.

7. K.B.Mc Grattan, G.P.Forney, J.E.Floyd, S.Hostikka, K.Prasad, Fire DynamicsSimulator-user's guide, version 3,NIST IR6784.Gaithersburg,MD:National Institute of Standards and Technology, 2001.

8. Adam B. Stein,Ephraim M. Sparrow,John M. Gorman. Numerical simulation of cables in widespread use in the nuclear power industry subjected to fire[J]. Fire Safety Journal,2012,53(6):28-34.

9. Ingason $\mathrm{H}, \mathrm{Li} \mathrm{Y}$ Z.Model scale tunnel fire tests with longitudinal ventilation[J].Fire Safety Journal,2010,45(6):371-384.

10. Artur Witkowski, Bertrand Girardin, Michael Försth,Fiona Hewitt,Gaëlle Fontaine, Sophie Duquesne,Serge Bourbigot, T. Richard Hull. Development of an anaerobic pyrolysis model for fire retardant cable sheathing materials[J]. Polymer Degradation and Stability,2015,113(1):208-217.

11. Dian Fan, Hongjun Ding, Dorothy Y. Wang, Desheng Jiang.Field test of optical and electrical fire detectors in simulated fire scenes in a cable tunnel[J].Photonic Sensors,2014,4(2):156-161.

12. Hai-jun tao, Guo-qing zhu, Yong-chang zhao. Golden pride Experimental study on combustion flue gas temperature of integrated pipe gallery and cable[J].Fire Science andtechnology, 2017, 4 (6) : 745-748.

13. LIU Yan, WU Jian-xing. Experimental Study on Effective Fire-extinguishing Technology for Cable Tunnel Fire[J]. Chinese Journal of Safety Science, 2008, 18(9). 